\title{
O papel social do desenho na formação do homem novo oitocentista
}

\section{The social role of drawing in the formation of the new nighteenth century man}

\author{
Gláucia Maria Costa Trinchão*
}

\begin{abstract}
RESUMO
Em uma vertente histórica, o artigo analisa e salienta a relação entre Desenho e Educação, levando em consideração o papel social do Desenho na formação profissional da infância e adolescência na virada do século XVIII ao século XIX, no ocidente. Reflete sobre a criação da escola pública e sua configuração ideológica e traz as propostas educativas para inserção desse saber nos espaços escolares, de ensino primário e secundário, como conhecimento importante para a formação da nova sociedade que precisava emergir e da nova mão de obra necessária ao desenvolvimento industrial que avançava no século XIX. Esta sociedade tinha o entendimento do desenho tanto enquanto conhecimento interdisciplinar quanto como um processo educativo do corpo, da mente e dos sentidos para a construção de um novo comportamento social, de civilidade, hábitos e valores sociais, findando por transformar essa linguagem em um instrumento de formação social e profissional pelo processo de alfabetização gráfica à visibilidade dos fundamentos das Artes e das Ciências, para a construção de um homem novo para atender a indústria (arte e técnica) nacional.
\end{abstract}

Palavras-chave: Ensino do Desenho. Educação. Formação profissional.

\begin{abstract}
On an historical point of view, this article analyses and focuses on the relation between Drawing and Education, considering the social role of Drawing in the professional development throughout childhood and adolescence in the turn of the XVIII century, in the West. It takes in consideration the ideology of it in the creation of the first and second grade public schools and brings

${ }^{*}$ Universidade Estadual de Feira de Santana. Feira de Santana, Bahia, Brasil. E-mail: gaulisy@gmail.com. https://orcid.org/0000-0002-0552-1089.
\end{abstract}


Drawing educational proposals to those educational spaces as an absolute necessity for the emergent new industrial society of the XIX century. This society regarded Drawing so much as a multidisciplinary knowledge like an educational process of mind, body and senses in the development of a new social behaviour with new social and moral values, ending in the creation of a so much needed new industrial man through the process of graphic alphabetization for the visibility of Arts and Sciences, one that could attend to the needs of the national (artistic and technical) industry.

Keywords: Drawing teaching. Education. Professional training.

\section{Introdução}

A História do Desenho, como conhecimento e saber escolar, sempre se misturou com várias outras Histórias, dentre elas a da Matemática, da Técnica e as História da Arte e do Trabalho, em suas duas acepções, como trabalho artesanal ou como bom gosto estético, pois o desenho sempre foi a base cientifica, a linguagem e o instrumento de socialização e de apreensão do conteúdo das ciências e da arte. A ligação entre Desenho, Ciências, Artes e Técnica sempre existiu e o Desenho dava visualidade aos fundamentos dessas. O Desenho serviu, e ainda serve, de instrumento para resolução dos problemas abstratos matemáticos, para os registros científicos na botânica, nas construções cartográficas e na arte da guerra, por exemplo, mesmo que os instrumentos atualmente utilizados para expressão dessa linguagem, materialização e visualização do seu conteúdo tenham se modernizado tecnologicamente.

O Desenho é um campo de conhecimento prático, à medida que ele se apresenta como conhecimento empírico, aquele que diz respeito à construção e utilização como linguagem adquirida pela interação e observação do indivíduo com o mundo, experiência, vivência. Enquanto Conhecimento teórico, depois de apreendido e cientificizado, quando o conhecimento adquirido pela experiência passa a ser admitido pela escola e pela ciência, se transforma em saber científico, quando então, suas funções, propósitos e fundamentos são comprovados e utilizados pela Ciência.

É no caminho da organização da história da Educação em Desenho, que se analisa aqui a relação entre desenho e educação, levando em consideração o papel social do Desenho escolar para a formação pessoal e profissional da infância e da adolescência oitocentista ocidental no contexto de mudanças e dinâmicas capitalistas que se impunham naquele período. A Educação aqui é vista 
como a relação entre ensinar e aprender, instruir, dar polidez e disciplinamento ao indivíduo, não só nos espaços escolares formais, para que hábitos, costumes e valores permitam transformar uma sociedade. O Desenho como campo de conhecimento, saber e linguagem, cuja teoria e a prática é capaz de reeducar o corpo, a mente e os sentidos.

O papel social do Desenho está aqui configurado como uma disciplina que, por si só, estabelece normas e regras na sua execução e que estabelece explicações, posturas e princípios que condicionam o comportamento dos indivíduos, pois trabalha a mente, a mão e os sentidos no despertar o bom gosto estético, para dar visualidade, socializar o imaginado, criado ou o copiado e o imitado, como era até as décadas finais do século XIX. Tais atributos do Desenho determinam interrelação do indivíduo com o grupo ao qual pertence ou com a instituição que o está formando. Logo, o desenho chega como um componente educacional que surge da interação social e tem como função dar acesso a seus fundamentos, sua didática e sua "gramática" própria a novos indivíduos e promover a formação de novos profissionais.

As propostas educativas para inserção desse saber nos espaços escolares oficiais de ensino primário e secundário no ocidente o defendiam como conhecimento importante para a formação da nova mão de obra, oriunda de segmentos sociais menos favorecidos, necessária à indústria que surgia no século XIX.

\section{A gênese da escola pública no século XIX e o papel do desenho}

Grandes transformações sociais e educacionais foram vivenciadas pelo mundo ocidental, associadas ao iluminismo do final do século XVIII, até início do século XX. Nesse período chamado de modernidade, dois eventos marcaram época: a Revolução Francesa e a Revolução Industrial. Transformações essas que romperam com o passado e com o pensamento religioso, valorizando a razão e promovendo a emancipação do homem. E foi aí que "a técnica e o método cientifico foram mais valorizados e se tornaram a base dos sistemas produtivos e do desenvolvimento social". (LUZ, 2013, p. 11). Nesse caminho, também o Desenho passou da mera experiência prática dos artífices e do ofício das artes Mecânicas, para um conhecimento teórico e prático necessário à formação de profissionais habilitados a atender às indústrias ocidentais.

Na Europa, do final do século XVIII, "toma corpo a ideia de estado-nação, enterrando-se de vez o que restava do mundo feudal, em termos políticos" (INÁCIO FILHO, 2009, p. 7). Nesse contexto, o estado burguês se estrutura e 
fortalece, configurando uma nova sociedade, cujo cerne das ações repousa nas ideias de Igualdade, Liberdade e Fraternidade, conceitos esses abstratos pois ao mesmo tempo em que eram subsídio ideológico para a ascensão ao poder, implementavam novas estruturas classistas, o que resultou em novas formas de opressão. O momento era de busca de estratégias para neutralizar as forças revolucionárias proletárias que ameaçam seu poder estabelecido no confronto com a monarquia.

A necessidade agora era de consolidação e fortalecimento de seu poder econômico e político, para isso o pensar em identidades nacionais era um ponto chave para a construção de um monopólio e de um Estado-nação fortalecido, concretizando um novo ideário, o ideário liberal. E é em defesa desse status que se pensa no processo educacional como questão central e necessária à construção de uma nova organização social, com objetivo principal de evitar a radicalização do movimento revolucionário proletário, ou seja, uma instituição que incidisse diretamente no cidadão que se queria formar para essa nova sociedade (GARCIA; LAZARINI, et. al, 2017). Nesse aspecto, ao mesmo tempo em que controlava e dissuadia, inseria o sujeito nas novas relações trabalhistas estabelecidas. Os outrora súditos agora seriam transformados em cidadãos e a escola foi parte fundamental nesse processo.

A criação da instituição escolar laica, pública e obrigatória se deu pautada em uma visão de formação de um sujeito a partir de valores morais e patriotas que o moldariam enquanto novo cidadão e lhe dariam uma consciência nacionalista e livre das influências religiosas. Era mister que o novo homem fosse educado para se adaptar ao novo modelo social capitalista e essa forma de educação foi um aparato para que a burguesia conseguisse implantar essa nova forma de controle social, econômico e político. Nesse contexto, o ensino do Desenho em escolas populares também serviu de instrumento de controle social, na medida em que sendo ensinado em escolas públicas proporcionaria uma espécie de concorrência com as corporações cujos espaços eram considerados como degradados. Esse processo de criação de escolas para o povo trouxe várias contradições na medida em que implementou um domínio político e econômico, mas também proporcionou certa emancipação aos trabalhadores que recebiam instrução, até então negada, e formação para sua inserção no mercado de trabalho capitalista, que se expandia e tomava proporções grandiosas.

Nesse aspecto, no século XIX, é estruturada "a escola de massa buscada como instrumento de construção da cidadania e sua expansão a todas as camadas e grupos sociais [...] maturando modelos de organização escolar”. A Europa do século XIX foi marcada pelo "processo de criação dos sistemas nacionais de educação" e pela nova forma de ver a infância (INÁCIO FILHO, 2009, p. 7).

Não podemos deixar de atentar que em todo esse processo de consti- 
tuição da escola pública, tendo como epicentro a luta de classes na França, as ideias estruturais para sua criação repousavam inicialmente nas formulações revolucionárias que pensavam em reformar o ensino popular em suas bases fundamentais, com o objetivo de constituir uma escola do povo, que atentasse para as necessidades da classe popular, que fosse configurada como escola para todos, pública, laica e gratuita e que oferecesse uma formação profissional elementar para todo e qualquer cidadão.

Apesar dos temores, de seus grupos mais tradicionais e também do alto clero, que viam no conhecimento um instrumento perigoso para a consciência de uma população que precisava ser controlada, a burguesia foi obrigada a ceder à educação pública. Devido às iniciativas populares e dos grupos revolucionários, a classe burguesa chega à conclusão de que essa educação não poderia mais ser adiada, sob a penalidade de ser criada por outras iniciativas e baseada em fundamentos que seriam perigosas ameaças à sua hegemonia e conservação de seu lugar social.

O novo cidadão seria instrumentalizado para o trabalho e não para participar das instâncias de decisões relativas à vida em sociedade. Controlando o processo educativo, a partir da anulação das iniciativas religiosas e sobretudo as reacionárias, quebrava-se os laços com os ideais religiosos de mundo e sociedade, e bloqueava-se um ideal socialista que repousava no seio dos movimentos revoltosos, formando assim um cidadão que defendia e sobretudo amava sua pátria, ou seja, uma educação com caráter acima de tudo moralizante que conformasse o novo cidadão à classe social estabelecida. "A burguesia tinha clareza do que queria da educação: trabalhadores com formação de cidadãos partícipes de uma nova sociedade liberal e democrática" (GADOTTI, 1993, p. 89). Sociedade em que as participações eram definidas e estabelecidas sob os interesses maiores de uma hegemonia dominante.

As discussões em torno dessa nova escolarização, seus conteúdos e currículo, ganharam o centro das atenções e foram influenciadas pelos diversos interesses ideológicos, políticos, econômicos e sociais. Foram vários os nomes que contribuíram para os debates educacionais e pensaram uma nova educação, nomes como Robespierre, Lepelletier, e, dentre outros, Condorcet. Os preceitos de Marie Jean Antoine Nicolas de Caritat, o Marquês de Condorcet, é o que se tem de mais elaborado na concepção liberal para a relação entre Estado e Escola (SAVIANI, 2008). Na França, Condorcet, deputado do Departamento de Paris, em 1792, e membro do Comitê de Instrução Pública, defendia a educação como meio de instruir as profissões. Profissões estas que ele dividiu em duas classes: 1. a classe das profissões que têm "como objetivo principal satisfazer as necessidades, aumentar o bem-estar, multiplicar os prazeres dos homens"; e 
2. a classe das profissões cuja "utilidade comum parece ser o primeiro objetivo [...] são de alguma forma função pública". (CONDORCET, 2008, p. 207).

É dessa primeira classe que fazem parte todos "os ofícios, todas as profissões mecânicas e mesmo as artes liberais", pois é o aumento progressivo de prazeres para "os pobres que se deve esperar do progresso geral das artes mecânicas". (CONDORCET, 2008, p. 209). A instrução desta classe profissional terá como vantagem "a igualdade entre os homens que praticam as artes; aproximará as crianças do artesão pobre daquelas do trabalhador mais rico", que pode dedicar recurso para aperfeiçoá-las na profissão. A instrução dessa classe de homens a quem a infelicidade e pobreza levam à corrupção, para Condorcet, é o meio de promover o aperfeiçoamento das instituições sociais (CONDORCET, 2008, p. 209). Esta ideia de educação e moralização dos espaços se tornou universal na Europa, e no Brasil.

Por trás da instrução das profissões estava o ensino e a socialização do Desenho no âmbito escolar público como meio de capacitação de segmentos sociais não-dominantes e a busca por melhorias na produção industrial. Esse argumento se iniciou no século XVIII, pois para "mostrar a utilidade do desenho", salientava-se a contribuição do Desenho Linear para o progresso artístico e industrial, por este aperfeiçoar o "gosto" e habilitar os técnicos, conduzindo o país e seu povo à prosperidade (D'ENFERT, 2007, p. 36).

No pensamento de Condorcet, a instrução deveria ser diferenciada para as duas classes de profissões que ele defendia. Para as artes mecânicas caberia oferecer apenas aqueles conhecimentos úteis a esta profissão e o desenho entra como o primeiro conhecimento a ser indicado para a instrução, por ser indispensável a "todas as artes do luxo, nas quais se associa a decoração à utilidade, e em todas as profissões em que se fabricam instrumentos empregados pelas outras artes". Depois, "vem Química, Princípios de Mecânica, Física e Aritmética Comercial, e algumas partes da Geometria Elementar". (CONDORCET, 2008, p. 210). A instrução desta classe deve ser diferenciada pela necessidade de cada profissão, a instrução de um chaveiro não deve ser igual a de um carpinteiro, como exemplo. "Difundindo mais luzes sobre a prática das artes, haverá mais operários hábeis e em maior número". (CONDORCET, 2008, p. 212).

Os promotores da inserção do Desenho na instrução pública francesa argumentavam que o Desenho era um meio de "regenerar e moralizar as classes pobres, favorecendo o progresso industrial e a prosperidade da nação", além de moralizar a classe técnica (D’ENFERT, 2007, p. 35). Por isso é possível compreender que o caráter social do Desenho se configura pelo saber que capacitaria pessoas de segmentos sociais distintos dos que frequentavam as antigas aulas de Desenho e os ateliês dos mestres/artesões.

Ao facilitar a inserção do Desenho no âmbito das mais variadas profissões 
se formaria a mão-de-obra técnica necessária à nação francesa, como "pedreiros, marceneiros, carpinteiros aparelhadores, serralheiros, talhadeiros, ladrilhadores, construtores de fogões", fabricantes de móveis, os "que trabalham nas coisas de moda e de gosto tal como os entalhadores, fundidores, douradores, relojoeiros, bronzeadores, marmoristas, alfaiates, modistas"; e os que se "entregam à execução das mecânicas ou dos instrumentos, tais como ópticos, engenheiros, mecânicos, fabricantes de tintas". (FRANCOEUR, 1839, p. 2).

Assim, a educação foi intimamente influenciada pela construção dos ideais de formação de Estados-nação e de uma classe trabalhadora, bem como de uma modernização econômica, social e produtiva que se configurou nos finais do século XIX. Dessa forma, na França se origina um sistema educativo moderno, que influencia toda a Europa e que fornecerá os fundamentos para a escola contemporânea. (CAMBI, 1999).

A proposta para a educação pública virou modelo para "projetos e parâmetros reformadores da instrução pública nos mais variados países do continente europeu (e, inclusive, na América Latina - muito particularmente no Brasil)". (BOTO, 2003, p. 741). Foi nesse contexto de mudanças que o Desenho passou a ser "vulgarizado" nos espaços escolares formais e se tornou livre das restrições de acesso ao seu conteúdo e práticas impostas pelas Corporações de Ofícios, Ateliês, Colégios Militares, Aulas de Artes Mecânicas, entre outros espaços de ensino informais. Podemos considerar a Escola de Ensino Mutuo, criada em 1815 , como o primeiro modelo francês de escola pública.

Nesse período, surge "o mito do desenvolvimento social através da educação", ao se propor "instituir civilidades, hábitos e valores" através dos "ideais de liberdade, igualdade e fraternidade", pelo "desenvolvimento cientifico" e pelo "surgimento das fábricas". (LUZ, 2013, p. 12).

Esta sociedade que emergia e se pretendia educada e controlada socialmente, tinha o entendimento do desenho tanto enquanto conhecimento útil a todas as profissões, quanto como um processo educativo do corpo, da mente e dos sentidos para a construção de um comportamento social, findando por transformar essa linguagem em um instrumento de formação social e profissional pelo processo de alfabetização gráfica à visibilidade dos fundamentos das Artes e das Ciências, para a construção de um homem novo que atenderia a indústria (arte e técnica) nacional.

No ensino do Desenho, como exemplos, o Desenho Técnico, a Geometria Descritiva e o Desenho Linear, por envolverem o Desenho de Observação e o Desenho Geométrico, e por exigir das faculdades de concentração e percepção além do uso de instrumentos, como compasso e régua, entram para os espaços escolares oitocentistas como efeito moralizador social e como capacitadores da sociedade que se queria na época. Isso porque se passou a entender que 
o Desenho tinha o potencial de "condicionar" o comportamento, estimular o gosto e de capacitar profissionalmente indivíduos, e deveria atender a segmentos sociais menos favorecidos, não só os que detinham acesso a ele até então, os indivíduos que frequentavam as antigas Guildas, as Aulas de Desenho, as Escolas Militares, os Ateliês dos Mestres artistas e artesões, assim como as aulas de Artes Mecânicas.

O Desenho chega como um conhecimento que prepara as classes populares para o trabalho industrial, e para isso passou a ser visto para além da sua acepção usual de mera representação gráfica, passando à linguagem técnica, além de se filiar "ao étimo desígnio, que é desejo, vontade, tenção" (ARTIGAS, 1981, p. 142). Concepção essa que Gama (1986, p. 110) chama de "face oculta do desenho", e que "assume grande importância a superação histórica da organização corporativa do trabalho", além de ser importante também com "as novas relações de produção e as novas maneiras de transmissão do conhecimento técnico, que rompem a disciplina e os segredos corporativos". A base dessa formação profissional formal começou pelo Desenho Linear, que foi criado na França para atender as escolas de Ensino Mútuo criadas em 1815, Escolas Mútuas da Restauração, escolas primárias que atendiam ambos os sexos (D’ENFERT, 2007).

\section{O ensino do Desenho: propostas educativas das oficinas à escola formal}

O papel social do desenho determinou a função dos indivíduos que viviam em Corporações, Ateliês, Escolas de Artes Mecânicas, dentre outros, na sociedade ocidental dos setecentos ao início dos oitocentos e nas escolas formais do início do século XIX. A passagem do desenho restrito ao desenho formalmente socializado se deu pela necessidade de se expandir as interações sociais, ou os processos de socialização, como meio de formar uma nova sociedade, gerando determinados comportamentos nos sujeitos a partir dos grupos escolares para que se estabelecesse uma espécie de concorrência entre os espaços corporativos e as escolas formais e assim esses espaços de acessos restritos passassem a receber aprendizes oriundos das escolas formais. Até o século XVIII arte e técnica sempre estiveram conectadas, o ofício mecânico trabalhava na produção de objetos de decoração de artefatos, ou produtos de uso no cotidiano, como portas, portões, grades, tecidos, azulejos, dentre outros.

A ideia de progresso foi o mote do século XIX, e o que "mantém essa concepção e a faz desenvolver são os progressos científico e técnico", além 
dos "sucessos da revolução Industrial, da melhoria, pelo menos para as elites ocidentais, do conforto, do bem-estar e da segurança, mas também os progressos do liberalismo, da alfabetização, da instrução e da democracia" (LUZ, 2013, p. 13-14). A "educação da nova geração nas artes deveria ser transferida da oficina para a escola, e a instrução prática teve que ceder, em parte, à instrução teórica, a fim de remover os obstáculos que o velho sistema colocava no caminho dos jovens talentos" (GAMA, 1986, p. 112).

O ensino de Desenho esteve, durante séculos, limitado às Corporações de ofícios, Grêmios e Guildas, como exemplos de corporações do trabalho artesanal, essas estabeleciam seu próprio processo de transmissão de conhecimento. Entretanto, "coincidentemente, o método científico de educação artística começou nas próprias oficinas". Já nos "quatrocentos os aprendizes eram familiarizados com os rudimentos da geometria, da perspectiva e da anatomia, além das lições referentes à prática, e iniciação no desenho do natural e no de bonecos". (GAMA, 1986, p. 112). Os mestres organizavam cursos nas oficinas e influenciavam a formação de estilos. Essas corporações tinham vários objetivos, dentre outros, "garantir o monopólio do exercício da profissão ou do ramo do comércio" e "controlar a qualidade e a quantidade das mercadorias produzidas". E, aqui destaque, "a formação profissional, através dos sistemas de aprendizado e do estabelecimento de regras rigorosas para o acesso à condição de oficial ou mestre no ofício respectivo". (GAMA, 1986, p. 83).

As guildas, corporações medievais, resistiram até o Renascimento. Por conta da necessidade de controlar a produção, no século XIV, surge outro modelo de corporação com uma estrutura mais moderna, as Corporações de Artes e Ofícios. Essas agrupavam "as associações de Artes Mecânicas", formadas por pessoas que tinham o mesmo Ofício, que tinham que fazer por obrigação ou dever "algum tipo especializado de trabalho". Esse trabalho que poderia ser "realizado manualmente e/ou com o auxílio de instrumentos era conhecido como um "ofício mecânico". Nessa época, "ofício e profissão possuíam significações equivalentes". Por sua vez, o "oficial mecânico" também era chamado de "artista mecânico" ou artesão, derivando-se desta designação as denominações de artista e artífice, verbetes que têm, entre dicionaristas dos séculos XVIII e XIX, acepções sobrepostas". (REIS, 2006, p. 12). O sistema "corporativo era o do aprendizado direto no trabalho", onde os aprendizes, entre 12 e 15 anos, moravam na oficina ou na residência do mestre, sendo "submetidos à vigilância, à disciplina e aos castigos físicos do mestre", donos das "ferramentas, dos utensílios, e da matéria prima". (GAMA, 1986, p. 86).

Nesse período de associações medievais de artesãos, as orientações de Comenius (1592-1670) estimulavam a instrução pública no aprender pela atividade prática do mesmo modo que se aprende nas artes mecânicas, "aprender a 
fazer fazendo". Em sua Didática Magna, o autor "pregava a educação da visão e da mente para o bom conhecimento das coisas, pois essas "caminham juntas e exigem sistematicamente a aplicação pela prática e pela utilidade" (COMENIUS, 2002, p. 232). Defendia a necessária instrução pública da classe popular e pregava a introdução do conhecimento em Desenho pela prática sistemática da imitação de objetos, para a educação da visão e da mente, para alcançar a perfeição, com abnegação da criatividade. Pelos sentidos e na relação intuitiva é que se iniciaria o conhecimento no processo ensino aprendizagem. Sua proposta didática tem base nas aplicações práticas dos mestres das artes mecânicas, da reprodução ou representação do objeto através da cópia do real, pois entende que estes "não ocupam as mentes dos seus aprendizes com discursos teóricos", eles "os levam prontamente a fazer as coisas para que aprendam a fabricar fabricando". Só os exercícios práticos e sistemáticos garantiriam a habilidade no Desenho e criariam o hábito da arte, "isso porque só a prática faz o artífice". (COMENIUS, 2002, p. 252).

$\mathrm{Na}$ sequência dos estudiosos que defendiam o saber em desenho em sala de aula, estava Rousseau, que em uma vertente naturalista, considerava que as crianças tentam desenhar porque são naturalmente grandes imitadoras. Ele defendia a presença do Desenho em uma Educação onde se primasse pelo olho justo e mão flexível, por meio da prática sistemática e repetição da cópia, ou imitação das formas, assim como Comenius.

O profundo conhecimento da forma, a perfeita imitação do objeto e a compreensão das leis da perspectiva são, na opinião de Rousseau (1992), requisitos básicos para a didática de ensino do Desenho. Para aprender a extensão e o volume dos corpos é preciso aprender e conhecer também suas formas, e até a imitá-las. O que importa no ato de desenhar para a criança não é a arte em si, mas "para tornar seu olho justo e sua mão flexível" e no geral não importa "que ela saiba tal ou qual exercício, desde que adquira a perspicácia do sentido e os bons hábitos do corpo que se ganham com o exercício". A criança deve aprender a traçar sempre com o objeto à sua frente, e não devendo fazê-lo nem de memória até que consiga, através de "observações frequentes", que suas formas exatas estejam impressas em sua imaginação. (ROUSSEAU, 1992, p. 145-146). Assim, a criança teria um "golpe de vista mais preciso, uma mão mais segura, o conhecimento das verdadeiras relações de formas e tamanhos", e "uma rápida experiência do jogo da perspectiva", a criança conheceria a forma e não precisaria imitá-la. As crianças, a partir da simples observação da forma e de suas combinações e organizações no espaço, deduziriam e aprenderiam as leis da perspectiva, por exemplo, assim como sobre a Geometria, que para Rousseau era "apenas arte de se servir da régua e do compasso", mas se deveria trocar os métodos racionais pelo método natural das crianças. (ROUSSEAU, 1992, p.146). 
A aprendizagem do Desenho em Comenius e Rousseau era pelo desenvolvimento da prática da observação e traçado sistemático de um objeto, como meio de se alcançar a educação do olho, da mente e consequentemente da mão, com vistas à apreensão das coisas materiais e do gosto pelas formas belas. $\mathrm{O}$ conhecimento deveria ser adquirido pela associação da brincadeira com a repetição sistemática das formas geométricas com precisão. (TRINCHÃO, 2008, p. 110).

Nas décadas iniciais do século XIX, o Desenho na educação popular pela prática e pela intuição chega seguindo os ideais humanistas que surgiram nas décadas finais do setecentos, nas propostas pedagógicas de Johann Heinrich Pestalozzi (1746-1827) e Friedrich A. Froebel (1782-1852). Pestalozzi investiu no ensino do desenho para a revitalização da humanidade, por isso ele trabalhava para as classes populares, buscando o Desenho e a Geometria que atuassem pela precisão do pensamento e da observação. Para o que ele chamava de ensino "inferior", ou ensino primário, os conhecimentos em Desenho, e para o ensino "superior", universitário, a Geometria e o Desenho.

A mecanização da instrução pela didática do ensino do Desenho de Pestalozzi vem da sua crença no Desenho como um meio de tornar o pensamento claro e preciso, por este estar ligado à percepção da forma e por exercitar a observação, condições básicas para o entendimento de sua doutrina da impressão sensorial como o fundamento de toda a instrução. Além disso, como o Desenho é naturalmente uma das formas de expressão da criança, para Pestalozzi, a primeira tentativa de simbolização linear, isso facilitaria naturalmente a escrita. Por conta da finalidade de se alcançar a escrita, pelo desenvolvimento das habilidades motoras, o Desenho livre de objetos era rigidamente excluído. (TRINCHÃO, 2008, p.112)

Froebel retoma princípios de Pestalozzi, porém, centra-se mais no interior do indivíduo e na tentativa de mediar sua externalização através da manipulação de objetos. Enquanto Pestalozzi destaca a importância da aquisição dos rudimentos do cálculo e da escrita em seu projeto Educacional, Froebel os substitui pela "brincadeira com as crianças", assim se estaria respeitando seu desenvolvimento natural (ARCE, 2002, p.199). O Desenho era base da manifestação da pintura e da escrita, uma disposição natural comum a todos os homens e por isso deveria ser cultivado desde a infância, pois a criança desenha antes mesmo de se desenvolver enquanto ser humano completo. Ele propõe o ensino de Desenho para todas as escolas rurais e urbanas, pois "se dirige ao entendimento, às faculdades intelectuais, ao espiritual do aluno [...] ao corporal, ao externo, à destreza da mão [...] desenterra o tédio [...] e a ociosidade", logo "desenvolve a visão para conhecer as formas e a mão para representá-las". (FROEBEL, 2001, p. 199). Em 1837, Froebel fundou, em Blankenburg, o Instituto de Educação Intuitiva, mais tarde chamado de Instituto Autodidático, para a autoeducação, onde aplicou 
sua pedagogia naturalista de busca do autoconhecimento com liberdade, em "um ambiente que fornecesse materiais para a criança expressar seu interior de maneira intuitiva", sem a pretensão de formar artistas, estimulando a apreciação estética das obras de arte adotando a brincadeira e o brinquedo como material didático, os "dons", a exemplo do conjunto de sólidos e elementos geométricos coloridos de madeira para o estudo das formas planas, para o ensino de Desenho e da Geometria. (ARCE, 2002, p.74).

Os trabalhos dos pedagogos Comenius, Rousseau, Pestalozzi e Froebel influenciaram a construção do caminho para a formalização do Desenho como disciplina escolar na instrução pública formal que capacitaria as classes menos favorecidas para atuarem em setores produtivos nos países ocidentais, inclusive no Brasil.

\section{O Desenho Linear, o ler, o escrever e o contar}

Apesar das propostas pedagógicas apresentadas nas décadas finais do século XVIII e início do século XIX, o modelo de escola popular que surgiu na França e se espalhou na Europa e no Brasil, foi o método de ensino Mútuo, um sistema de ensino barato e eficaz capaz de ilustrar a população mais pobre, que foi sistematizado, separadamente, pelo médico e pastor anglicano A. Bell (1753-1832) e pelo membro da seita dos Quackers J. Lancaster (1778-1838). "No método mútuo a responsabilidade é dividida entre o professor e os monitores, visando uma democratização das funções de ensinar" e atende a um contingente grande de alunos (BASTOS, 1997, p.117), ao contrário do que se aplicava nas antigas corporações de ofícios e ateliês. A intenção era que com a inserção do desenho nesse sistema de ensino, a qualidade nos hábitos, comportamento, costumes e profissional melhoraria e, assim, estimularia os mestres artesãos a procurarem os alunos das escolas mútuas, promovendo uma espécie de concorrência com as escolas de desenho. O saber em Desenho, teórico e prático, sai desses espaços de acesso restrito e se expande ao passar a ser um dos quatro saberes escolares, junto ao ler, o escrever, e o contar, desde a implantação das Escolas de Ensino Mútuo. Assim, se altera o velho sistema de aprendizagem por corporações e o monopólio do ensino retido por elas, o Desenho e o desenhar passam para dentro de espaços escolares formais.

As Escolas de ensino mútuo iniciadas na França pela Société pour l'instruction élementaire (SIE), em 1815, chegam também ao Brasil (BASTOS, 1997). O Desenho Linear, "arte de imitar o contorno dos corpos e de suas 
partes com a ajuda de linhas simples, e sem o recurso de sombras nem cores" (FRANCOEUR, 1839, p. 5), entra no sistema educação, não só francês, mas de vários outros países, inclusive no Brasil também, coadjuvando o ler, o escrever e o contar nas escolas primárias. "Na realidade, o Desenho Linear engloba, sobretudo um método de ensino elementar de Desenho, isto é, um conjunto de procedimentos didáticos que fornece os elementos" para subsidiar o ensino de Desenho em espaço escolar. (D’ENFERT, 2007, p. 43).

Tinha uma finalidade moralizadora a partir do momento em que se pretendia desenvolver "hábitos de ordem e de disciplina", assim como, "o gosto pelo trabalho bem feito". Acreditava-se que assim se abriria concorrência nas antigas escolas geridas por "mestres-artesãos". As qualidades adquiridas com o desenhar fariam "com que os antigos alunos das escolas mútuas", fossem "procurados pelos mestres artesãos", promovendo concorrência "com as escolas de desenho" (D'ENFERT, 2007, p. 35).

O ensino do Desenho Linear teve efeito moralizador na medida em que ele capacitaria pessoas de segmentos sociais distintos dos que frequentavam as antigas aulas de Desenho e os ateliês dos mestres/artesãos. Nessa perspectiva, "oferecer lições de desenho linear na escola mútua" era, "graças a um ensino reputado útil", dar prolongamento a "uma educação moral iniciada desde as primeiras aprendizagens da leitura e da escrita", coisa que "as escolas de desenho não ofereciam realmente". Assim, o Desenho Linear, considerado como a base da formação profissional, passou a ser visto como "uma alternativa à aprendizagem precoce em ateliê", espaço "onde os jovens correm os riscos de conviver com os técnicos cujas qualidades morais não são sempre comprovadas". (D'ENFERT, 2007, p. 35).

O papel social do Desenho Linear com sua inserção no sistema público de ensino elementar se diferenciou em gênero, principalmente nas escolas urbanas, pois conforme d'Enfert (2007, p. 38), o ensino do Desenho atendia tanto ao público masculino, ao ser direcionado para o "mundo do artesanato", quanto ao público feminino, pois o Desenho entrava para habilitar as mulheres nos "trabalhos de costura", com o fim de atender "às futuras tarefas femininas", tanto as profissionais, nas futuras atividades têxteis, quanto nas tarefas domésticas de "coser ou consertar roupas".

Com a inserção de mais disciplinas no ensino primário, principalmente a de Desenho Linear, se pretendeu manter "por mais tempo os alunos na escola primária". Nesse caminho "o ensino do desenho linear aparece, consequentemente como uma forma "conservadora" ou de "regulação social", que "responde plenamente aos projetos políticos" da monarquia francesa, (D'ENFERT, 2007, p.35).

Por trás da socialização do Desenho Linear, além da moralização e capacitação de segmentos sociais não-dominantes, estava a busca por melhorias na 
produção industrial. Nesse discurso, criado para defender a inserção do Desenho no âmbito escolar, iniciado no século XVIII, pois para "mostrar a utilidade do desenho" se salientava a contribuição do Desenho Linear para o progresso artístico e industrial, este aperfeiçoava o "gosto" e habilitava os técnicos, conduzindo o país e seu povo à prosperidade (D'ENFERT, 2007, p. 36).

Era preciso levar em conta também o vínculo do ensino de Desenho com as ambições industriais e com as "evoluções técnicas do momento", oriundas desse setor. Os novos caminhos que seguia a indústria colocaram as antigas Escolas de Desenho como "impróprias para uma verdadeira educação moral dos técnicos". Dessa forma, essas escolas foram "igualmente desqualificadas quanto a sua capacidade de formar técnicos para a indústria", pois detinham um ensino "julgado muito artístico" ao contrário do que se propunha com o Desenho Linear, um Desenho mais técnico e científico aplicado à indústria, que "aparece sobretudo como a disciplina específica das artes mecânicas”. (D’ENFERT, 2007, p. 36).

Os propósitos do Desenho Linear estavam no ensino científico do Desenho e na sua aplicação na construção e reprodução de objetos que caracterizam a base de certas profissões, como marcenaria, arquitetura e serralheria, dentre outras, assim como dar a base para a escolha futura do caminho profissional a seguir pelo alunado. O Desenho Linear em sua especificidade técnica, "remete à precisão do grafismo, que se inscreve menos na perspectiva estética [...] do que uma vontade de recuperar o atraso técnico em relação à Inglaterra" tanto na indústria do ferro quanto na construção mecânica (D'ENFERT, 2007, p. 36). O Desenho Linear, portanto, foi um dos principais saberes que auxiliaram o processo de ensino-aprendizagem do ler, escrever e contar nas escolas primárias, principalmente as que utilizaram o sistema de ensino mútuo, tanto na França quanto no Brasil e Portugal.

\section{Considerações finais}

Como parte estruturante da nova sociedade, o Desenho teve papel determinante, sendo também considerado como a base da formação profissional e, por conta disso, sua inserção era necessária nos espaços escolares desde as primeiras letras. O objetivo maior dessa proposta pedagógica era desenvolver o gosto pelo trabalho e o aprimoramento da qualidade do produto final. Com isso, possibilitando a concorrência com as antigas Escolas de Desenho geridas por "mestres-artesãos", promovendo assim um confronto entre esses artesões e o profissional de formação técnica. 
O papel social do Desenho Linear atendia tanto ao público masculino, para o artesanato e as atividades industriais, quanto ao feminino, para atividades domesticas (costura e bordado) e profissionais (atividades têxteis). O acesso ao saber em Desenho e principalmente, a instrução como um todo, possibilitariam uma certa promoção social ao permitir a revelação de talentos e competências de segmentos sociais não-dominantes.

Não podemos esquecer que no projeto da educação pública subvertido pela burguesia, pensou-se em uma educação para o povo e não do povo, cujas bases e fundamentos se estruturam a partir de um ensino baseado em valores específicos com princípios e deveres morais e cívicos que ensinassem a criança o dever e amor à pátria, bem como princípios conservadores da sociedade que se estruturariam como base essencial dos currículos escolares. Nesse processo, o desenho foi um dos componentes curriculares que contribuiu para a formação desse novo cidadão trabalhador, inserido no contexto capitalista.

O ensino do desenho foi importante para condicionar e conformar esse indivíduo ao sistema, um componente educacional que proporcionaria conhecimento estruturante a formação dessa nova mão de obra, na medida em que favorece o desenvolvimento sensorial e com ele habilidades diversas, sendo pensado enquanto base de formação profissional, mas também moralizadora. E nesse aspecto, o Desenho se configurou como conhecimento útil em muitos aspectos e serviu tanto para emancipação da classe popular, como para instrumento auxiliar aos propósitos dos novos interesses sociais que estruturavam a sociedade.

\section{REFERÊNCIAS}

ARTIGAS, J. B. V. Caminhos da Arquitetura. São Paulo: Cosac \& Naify, 1981.

BASTOS, M. H. C. A instrução pública e o ensino mútuo no Brasil: uma história pouco conhecida. (1808-1827). História da Educação. ASPHE/FaE/UFpel, Pelotas (1): 115133. Abr. 1997.

BOTO, C. A escola do homem novo: entre o iluminismo e a Revolução Francesa. São Paulo: Editora Unesp, 1996.

CAMBI, F. História da pedagogia. 3. reimp. São Paulo: Editora UNESP, 1999.

CONDORCET, J. A. N. de C., Marquis. de, 1743-1794. Cinco memórias sobre a instrução pública/Condocert. Tradução e apresentação Maria das Graças de Souza. São Paulo: Editora UNESP, 2008. 
D’ENFERT, R. Uma nova forma de ensino de desenho na França no início do século XIX: o desenho linear. Tradução Maria Helena Câmara Bastos. História da Educação. ASPHE/UFPel (mai/ago 2007). p.31-60.

FRANCOEUR, L. Dessin linéaire et arpentage, pour toutes lês égoles primaires, quel que soit le mode d'instruction qu'on y suit. 4. ed. Paris: Chez Louis Colar et Chez Bachelier, 1839.

GAMA, R. A tecnologia e o trabalho na história. São Paulo: Nobel: Editora USP, 1986.

GADOTTI, M. História das ideias pedagógicas. São Paulo: Ática, 1993.

GARCIA, J. D. A.; LAZARINI, A. Q.; BARBIERI, A. F.; MELLO, R. A. A origem da escola pública no séc. XIX: contraposição ou coerência com as necessidades do capital?. Revista Tempos e espaços em educação. São Cristovão-SE, v. 10. n. 21, p. 177-190. jan/ abr 2017. Disponível em: https://seer.ufs.br/index.php/revtee/article/view/6341. Acesso em: 19 mai. 2018.

INÁCIO FILHO, G. Apresentação do Livro. In: ARAÚJO, M. M. (Org). História(s) Comparada(s)da Educação. Brasília: Liber Livros, 2009.

REIS, L. A Liberdade que vem do Oficio. Práticas Sociais e Cultura dos Artífices na Bahia do século XIX. Tese (Doutorado em História). Universidade Federal da Bahia, Programa de Pós-Graduação em História. Salvador, 2006.

Texto recebido em 12 de novembro de 2018.

Texto aprovado em 14 de dezembro de 2018. 